\title{
Super-Exchange Interaction in a Chair-Piperazine Bridged Dicopper(II/II) Complex: Synthesis, Crystal Structure, Magnetic Properties and Molecular Orbital Calculations
}

\author{
C. T. Zeyrek ${ }^{\mathrm{a}}$, A. Elmali ${ }^{\mathrm{b}}$, and Y. Elerman ${ }^{\mathrm{b}}$ \\ a Turkish Atomic Energy Authority, 06690 Lodumlu-Ankara, Turkey \\ b Department of Engineering Physics, Faculty of Engineering, Ankara University, \\ 06100 Besevler-Ankara, Turkey \\ Reprint requests to Dr. C. Zeyrek. E-mail: zeyrek@taek.gov.tr
}

Z. Naturforsch. 61b, 237 - 242 (2006); received October 13, 2005

\begin{abstract}
Reaction of the $\mu$-bis(tridentate) ligand $\mathrm{H}_{3} \mathrm{~L}^{\prime}$ ( $\mathrm{L}^{\prime}=1,3$-bis[N-(5-chloro-2-hydroxybenzylidene)2-aminoethylene]-2-(5-chloro-2-hydroxyphenyl)imidazolidine) with copper(II) chloride dihydrate gives the chair-piperazine bridged complex $\left[\mathrm{Cu}_{2}(\mu-\mathrm{L}) \mathrm{Cl}_{2}\right]$. The halves of the binuclear complex are related by crystallographic inversion symmetry. The intramolecular $\mathrm{Cu} \cdots \mathrm{Cu}$ separation is 6.954(3) A. Temperature-dependent magnetic susceptibility measurements of the complex show a weak intramolecular antiferromagnetic coupling. The super-exchange coupling constant $(J)$ is $-10.5 \mathrm{~cm}^{-1}$. Semi-empirical extended Hückel molecular orbital (EHMO) calculations have been performed in order to gain insight into the molecular orbitals that participate in the super-exchange pathway.
\end{abstract}

Key words: Dinuclear Copper(II) Complex, Super-Exchange Interactions, Antiferromagnetic Coupling, Schiff Base, Imidazolidine

\section{Introduction}

Series of binuclear transition-metal complexes which display interesting physical properties have been intensively investigated during the last two decades. This is partly due to their relevance as active site structures of metal-proteins and enzymes [1,2], and partly because of attempts to understand the relationship between the structure and the magnetic properties [3-7]. Many of the studies have been concerned with exchange interactions in binuclear copper(II) complexes and the results have indicated that the strength of the exchange interaction depends primarily upon the symmetry and energy of the copper(II) ion ground state relative to the highest occupied molecular orbitals of the bridging moiety. The complexes exhibit ferromagnetic or antiferromagnetic character depending on their geometry.

The nature and number of metal ion coordination of linear hexadentate ligand can be altered [8] with the insertion of a spacer group such as imidazolidine, forcing the parent hexadentate ligand to act as a bis(tridentate) and/or bis(tetradentate) one. Chelating arm-substituted 1,4-piperazine can bind metal ions in both the boat and chair conformations of which the later is thermodynamically more favorable [9]. The boat form gives mononuclear complexes [10], whereas the chair form can give dinuclear complexes with no exogenous bridging for trans- $N, N^{\prime}$-coordination.

Very recently, we reported the syntheses, structural characterization and conformational analysis of the ligand $\mathrm{H}_{3} \mathrm{~L}^{\prime}$ (Fig. 1) and its mononuclear iron(III) complex [11]. We also reported the magnetic properties of its dinuclear iron(III) complex [12]. Herein we report the complexation behavior of copper(II) towards the $\mu$-bis(tridentate) ligand $\left(\mathrm{H}_{3} \mathrm{~L}^{\prime}\right)$. The ligand reacts with copper(II) chloride dihydrate in methanol to form the dinuclear $\left[\mathrm{Cu}_{2}(\mu-\mathrm{L}) \mathrm{Cl}_{2}\right]$ complex with the imidazolidine ring transformed into chair-piperazine by hydrolysis (Fig. 1). We present the synthesis, crystal structure and magnetic properties of the chair-piperazine bridged dicopper(II/II) complex $\left[\mathrm{Cu}_{2}(\mu-\mathrm{L}) \mathrm{Cl}_{2}\right]$ of the new piperazino $\mu$-bis(tridentate) ligand $\left\{N, N^{\prime}\right.$-bis $[2-$ (5-chlorosalicylaldimino)ethyl]piperazine $\}\left(\mathrm{H}_{2} \mathrm{~L}\right)$. We also performed extended Hückel molecular orbital (EHMO) calculations to determine the nature of the frontier orbitals. 


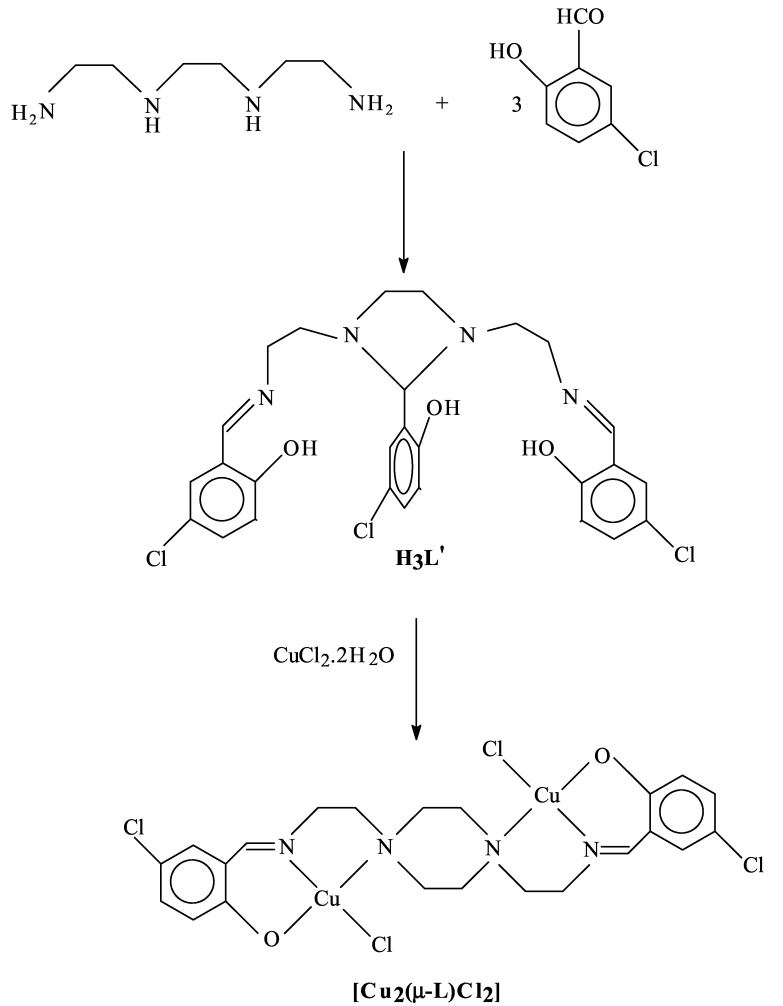

Fig. 1. Schemes of $\left[\mathrm{Cu}_{2}(\mu-\mathrm{L}) \mathrm{Cl}_{2}\right]$ and $\mathrm{H}_{3} \mathrm{~L}^{\prime}$.

\section{Experimental Section}

Preparation of $\left[\mathrm{Cu}_{2}(\mu-L) \mathrm{Cl}_{2}\right]$

The dinuclear copper(II/II) complex was prepared in two steps. A solution of triethylenetetramine $(2.2 \mathrm{~g}, 15 \mathrm{mmol})$ in methanol $(20 \mathrm{ml})$ was added dropwise to a methanolic solution $(40 \mathrm{ml})$ of 5-chlorosalicylaldehyde $(6.32 \mathrm{~g}, 45 \mathrm{mmol})$ with stirring at room temperature. The Schiff base ligand was obtained in the form of yellow crystals $\left(\mathrm{H}_{3} \mathrm{~L}^{\prime}\right)$ (Fig. 1). For the preparation of the copper(II/II) complex, the Schiff base ligand $\mathrm{H}_{3} \mathrm{~L}^{\prime}(1.15 \mathrm{~g}, 2 \mathrm{mmol})$ was dissolved in hot methanol $(70 \mathrm{ml})$ and a solution of copper(II)chloride dihydrate $(0.54 \mathrm{~g}, 4 \mathrm{mmol})$ in $50 \mathrm{ml}$ of methanol was added with stirring for $5 \mathrm{~min}$. The blue solution was allowed to evaporate at room temperature over one day to give prismatic blue crystals, which were collected, washed with cold absolute ethanol and finally dried in air. $\mathrm{C}_{22} \mathrm{H}_{24} \mathrm{Cl}_{4} \mathrm{Cu}_{2} \mathrm{~N}_{4} \mathrm{O}_{2}$ (645.33): calcd. C 40.95, H 3.71, N 8.66, Cu 9.85; found C 41.05, H 3.59, $\mathrm{N} 8.76, \mathrm{Cu} 9.91$.

\section{$X$-ray structure determination}

A crystal of dimension $0.40 \times 0.30 \times 0.04 \mathrm{~mm}^{3}$ was mounted on an Enraf-Nonius CAD 4 diffractometer [13] and investigated with graphite monochromatized Mo- $\mathrm{K}_{\alpha}$ radiation $(\lambda=0.71073 \AA)$. Experimental conditions are summa-
Table 1. Crystallographic data for the investigated complex.

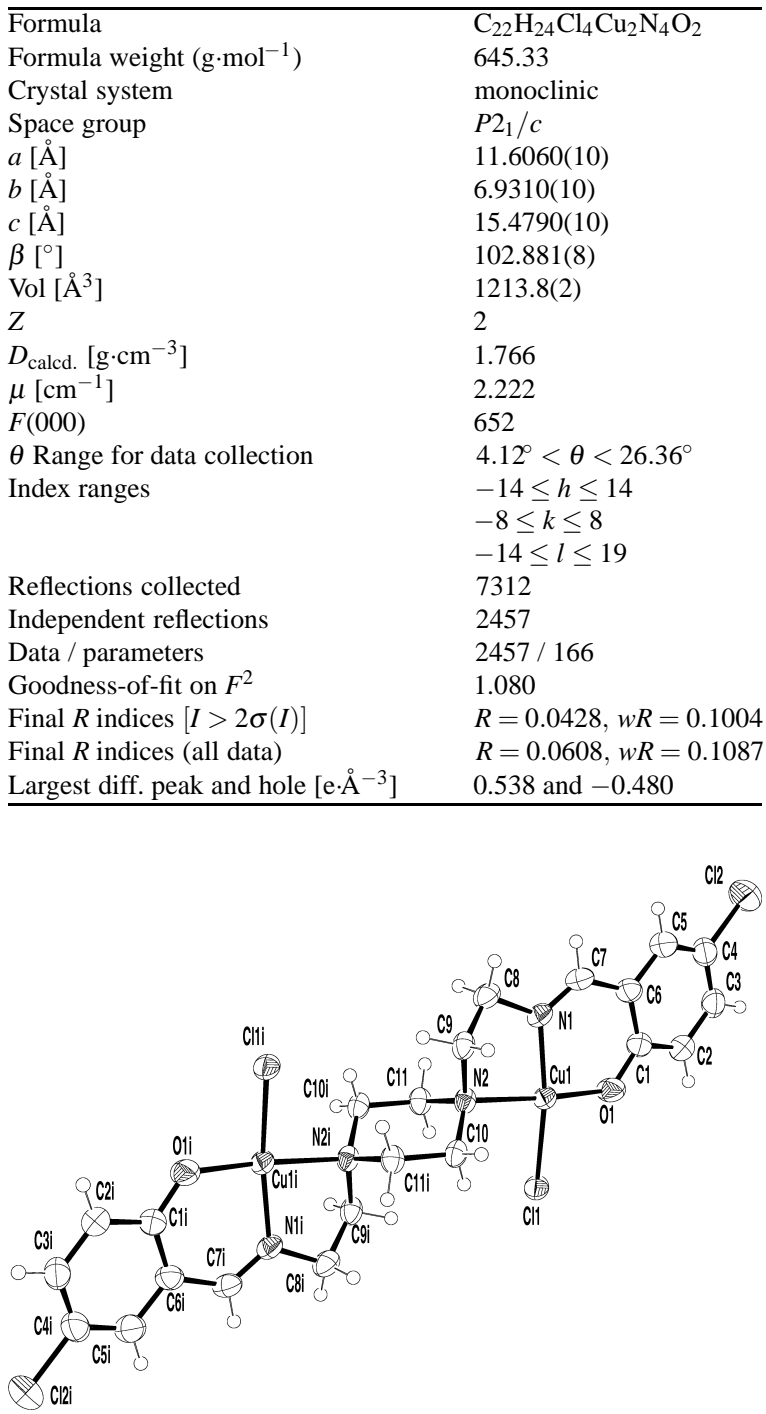

Fig. 2. View of the molecule. Displacement ellipsoids are plotted at the $50 \%$ probability level.

rized in Table 1. Precise unit cell dimensions were determined by least-squares refinement on the setting angles of 25 reflections $\left(4.12^{\circ} \leq \theta \leq 26.36^{\circ}\right)$ carefully centered on the

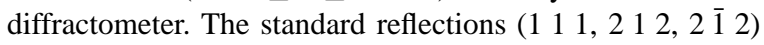
were measured every $7200 \mathrm{~s}$ and the orientation of the crystal was checked after every 600 reflections. A total of 7312 reflections were recorded, with Miller indices $h_{\min }=-14$, $h_{\max }=14, k_{\min }=-8, k_{\max }=8, l_{\min }=-14, l_{\max }=19$. Data reduction and corrections for absorption and decomposition were achieved using the Nonius Diffractometer Control Software [13]. The structure was solved by SHELXS-97 [14] and refined with SHELXL-97 [15]. The positions of the $\mathrm{H}$ atoms 
Table 2. Atomic coordinates and equivalent isotropic displacement parameters $\left(\AA^{2}\right)$ of the non-hydrogen atoms.

\begin{tabular}{lllll}
\hline Atom & $x$ & $y$ & $z$ & ${ }^{*} U(\mathrm{eq})$ \\
\hline C1 & $0.2144(3)$ & $0.4884(5)$ & $0.3024(2)$ & $0.0399(9)$ \\
C2 & $0.1592(4)$ & $0.5743(7)$ & $0.3653(2)$ & $0.0470(10)$ \\
C3 & $0.0741(4)$ & $0.4797(6)$ & $0.3984(3)$ & $0.0496(11)$ \\
C4 & $0.0413(4)$ & $0.2941(7)$ & $0.3705(3)$ & $0.0518(11)$ \\
C5 & $0.0902(4)$ & $0.2051(6)$ & $0.3089(3)$ & $0.0507(11)$ \\
C6 & $0.1760(3)$ & $0.3001(6)$ & $0.2725(2)$ & $0.0396(9)$ \\
C7 & $0.2131(3)$ & $0.2086(6)$ & $0.1998(2)$ & $0.0412(9)$ \\
C8 & $0.2990(3)$ & $0.1837(5)$ & $0.0746(2)$ & $0.0402(9)$ \\
C9 & $0.4231(3)$ & $0.2284(5)$ & $0.0642(2)$ & $0.0361(8)$ \\
C10 & $0.5747(3)$ & $0.4786(6)$ & $0.0868(2)$ & $0.0337(8)$ \\
C11 & $0.3802(3)$ & $0.5540(6)$ & $-0.0030(2)$ & $0.0340(8)$ \\
N1 & $0.2801(3)$ & $0.2837(4)$ & $0.15340(18)$ & $0.0348(7)$ \\
N2 & $0.4458(3)$ & $0.4387(4)$ & $0.07532(17)$ & $0.0309(6)$ \\
O1 & $0.2948(2)$ & $0.5859(4)$ & $0.27484(17)$ & $0.0469(7)$ \\
C11 & $0.45653(9)$ & $0.81472(12)$ & $0.19495(5)$ & $0.0400(3)$ \\
C12 & $-0.06756(13)$ & $0.1765(2)$ & $0.41335(9)$ & $0.0868(5)$ \\
Cu1 & $0.37567(4)$ & $0.51537(6)$ & $0.18452(3)$ & $0.03285(17)$ \\
\hline
\end{tabular}

${ }^{*} U(\mathrm{eq})=(1 / 3) \Sigma_{i} \Sigma_{j} U_{i j} a_{i}^{*} a_{j}^{*} a_{i} a_{j}$.

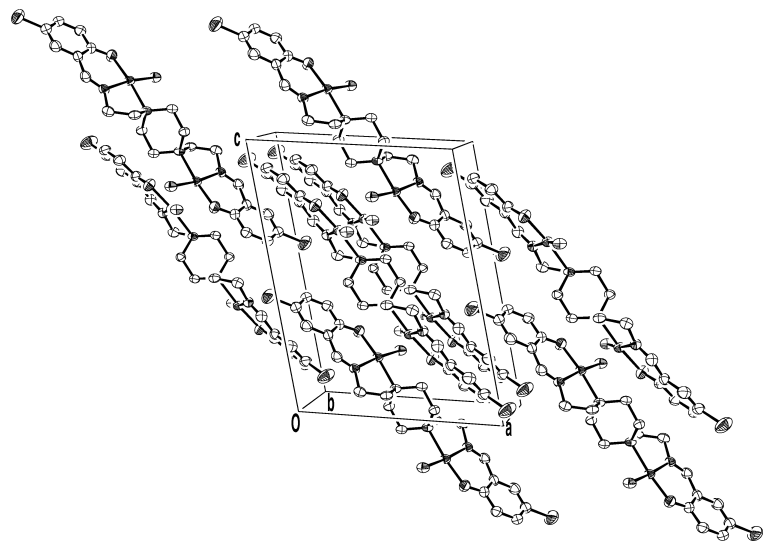

Fig. 3. Unit cell packing diagram of $\left[\mathrm{Cu}_{2}(\mu-\mathrm{L}) \mathrm{Cl}_{2}\right]$.

bonded to $\mathrm{C}$ atoms were calculated (C-H distance $0.96 \AA$ ), and refined using a riding model. $\mathrm{H}$ atom displacement parameters were restricted to be $1.2 \mathrm{U}_{\mathrm{eq}}$ of the parent atom. The final positional parameters are presented in Table 2. A perspective drawing of the molecule is shown in Fig. 2 [16]. The packing diagram for $\left[\mathrm{Cu}_{2}(\mu-\mathrm{L}) \mathrm{Cl}_{2}\right]$ is shown in Fig. 3. Selected bond lengths and angles are summarized in Table 3. Crystallographic data (excluding structure factors) for the structure reported in this paper have been deposited with the Cambridge Crystallographic Data Centre as supplementary publication no. CCDC-283155 [17].

\section{Susceptibility measurements}

Variable-temperature magnetic susceptibility measurements of a powdered sample were performed with a QUANTUM Design SQUID magnetometer in the temperature range $4.6-301 \mathrm{~K}$. The applied field was $1 \mathrm{~T}$. Dia-
Table 3. Selected bond lenghts $(. \AA)$ and bond angles $\left(^{\circ}\right)$ characterizing the inner coordination sphere of the copper(II) centers (see Fig. 2 for labeling scheme adopted).

\begin{tabular}{llll}
\hline $\mathrm{Cu} \cdots \mathrm{Cu}^{\mathrm{a}}$ & $6.954(3)$ & & \\
$\mathrm{N} 1-\mathrm{Cu} 1$ & $1.950(3)$ & $\mathrm{N} 2-\mathrm{Cu} 1$ & $2.101(3)$ \\
$\mathrm{O} 1-\mathrm{Cu} 1$ & $1.913(3)$ & $\mathrm{C} 11-\mathrm{Cu} 1$ & $2.268(1)$ \\
$\mathrm{Cu} 1-\mathrm{Cl} 1$ & $2.755(1)$ & $\mathrm{C} 1-\mathrm{O} 1$ & $1.299(4)$ \\
$\mathrm{C} 7-\mathrm{N} 1$ & $1.281(5)$ & $\mathrm{C} 8-\mathrm{N} 1$ & $1.461(4)$ \\
$\mathrm{C} 9-\mathrm{N} 2$ & $1.484(4)$ & $\mathrm{C} 10-\mathrm{N} 2$ & $1.492(5)$ \\
$\mathrm{C} 7-\mathrm{N} 1-\mathrm{C} 8$ & $119.9(3)$ & $\mathrm{C} 7-\mathrm{N} 1-\mathrm{Cu} 1$ & $125.4(2)$ \\
$\mathrm{C} 8-\mathrm{N} 1-\mathrm{Cu} 1$ & $114.4(2)$ & $\mathrm{C} 9-\mathrm{N} 2-\mathrm{C} 10$ & $110.1(3)$ \\
$\mathrm{C} 9-\mathrm{N} 2-\mathrm{C} 11$ & $112.4(3)$ & $\mathrm{C} 10-\mathrm{N} 2-\mathrm{C} 11$ & $108.1(3)$ \\
$\mathrm{C} 9-\mathrm{N} 2-\mathrm{Cu} 1$ & $104.5(2)$ & $\mathrm{C} 10-\mathrm{N} 2-\mathrm{Cu} 1$ & $114.6(2)$ \\
$\mathrm{C} 11-\mathrm{N} 2-\mathrm{Cu} 1$ & $107.2(2)$ & $\mathrm{C} 1-\mathrm{O} 1-\mathrm{Cu} 1$ & $127.8(2)$ \\
$\mathrm{Cu} 1-\mathrm{Cl} 1-\mathrm{Cu} 1$ & $136.8(1)$ & $\mathrm{O} 1-\mathrm{Cu} 1-\mathrm{N} 1$ & $92.6(1)$ \\
$\mathrm{O} 1-\mathrm{Cu} 1-\mathrm{N} 2$ & $173.5(1)$ & $\mathrm{N} 1-\mathrm{Cu} 1-\mathrm{N} 2$ & $83.9(1)$ \\
$\mathrm{O} 1-\mathrm{Cu} 1-\mathrm{Cl} 1$ & $88.7(2)$ & $\mathrm{N} 1-\mathrm{Cu} 1-\mathrm{Cl1}$ & $167.0(2)$ \\
$\mathrm{N} 2-\mathrm{Cu} 1-\mathrm{Cl} 1$ & $93.5(2)$ & $\mathrm{O} 1-\mathrm{Cu} 1-\mathrm{Cl} 1$ & $91.3(2)$ \\
$\mathrm{N} 1-\mathrm{Cu} 1-\mathrm{Cl} 1$ & $91.7(2)$ & $\mathrm{N} 2-\mathrm{Cu} 1-\mathrm{Cl1}$ & $94.3(2)$ \\
$\mathrm{C} 11-\mathrm{Cu} 1-\mathrm{Cl} 1$ & $101.2(1)$ & & \\
$\left.{ }_{\mathrm{a}}{ }^{-}-x, 1-y,-z\right)$. & & &
\end{tabular}

magnetic corrections of the molar magnetic susceptibility were applied using Pascal's constant [18]. The effective magnetic moments were calculated by the equation $\mu_{\mathrm{eff}}=$ $2.828(\chi \mathrm{T})^{1 / 2}$, where $\chi$ is the magnetic susceptibility per $\mathrm{Cu}(\mathrm{II})$ ion.

\section{Molecular orbital calculations}

Extended Hückel molecular orbital (EHMO) calculations have been performed in order to gain insight into the molecular orbitals that participate in the super-exchange pathway by using the Computer Aided Composition of Atomic Orbitals (CACAO) package programs [19]. The interatomic distances were taken from the X-ray results. Molecular orbital representations were plotted using the CACAO software [19].

\section{Results and Discussion}

\section{$X$-ray crystal structures}

The halves of the chair-bridged $\left[\mathrm{Cu}_{2}(\mu-\mathrm{L}) \mathrm{Cl}_{2}\right]$ binuclear complex are related by crystallographic inversion symmetry. The structure of the dicopper complex has singly bridged near square-planar coordination geometry of the metal atoms with no short intermolecular contacts between the dinuclear units. The $\mathrm{N} 1, \mathrm{~N} 2, \mathrm{O} 1, \mathrm{Cl1}$, and $\mathrm{Cu}$ atoms lie approximately in a plane. The atom with the greatest deviation from the $\left[\mathrm{CuN}_{2} \mathrm{OCl}\right]$ plane is the $\mathrm{Cu}$ atom at $0.135(1) \AA$. The two copper atoms are bridged by a chair-shaped piperazine fragment of $\mathrm{L}^{2-}$. The distance between the $\mathrm{Cu} 1$ and $\mathrm{Cu} 1^{\mathrm{i}}$ [symmetry transformation used to generate equivalent atoms: $\left.{ }^{\mathrm{i}}(1-x, 1-y,-z)\right]$ centers in 


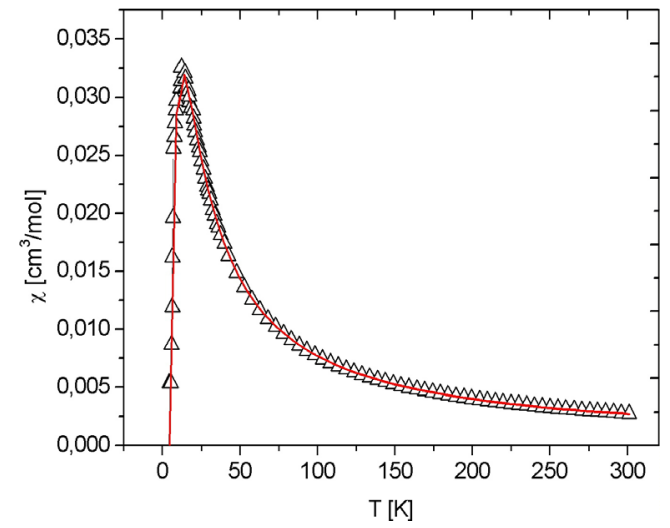

Fig. 4. The molar magnetic susceptibilities $\chi$ per copper(II) $v s$. temperature $T$ curves.

the dimer is 6.954(3) $\AA$. The $\mathrm{N}_{\text {pip }}-\mathrm{N}_{\text {pip }}$ distance is 3.007(2) $\AA$.

The coordination sphere of each copper atom contains two cis nitrogen atoms $(\mathrm{Cu}-\mathrm{N}(1)=1.950(3) \AA$, $\mathrm{Cu}-\mathrm{N}(2)=2.101(3) \AA)$ (coordination to imine $\mathrm{sp}^{2}$ and piperazine $\mathrm{sp}^{3}$ nitrogen atoms is clearly reflected in the bond distance difference), one phenolic oxygen $(\mathrm{Cu}-\mathrm{O}(1)=1.913(3) \AA)$ of the $\mu$-bis(tridentate) ligand and one chlorine atom. The $N, N$-bridging mode of piperazine in the dicopper(II/II) complex is similar to that characterized earlier for acetate and dimethylformamide (DMF) coordinated neutral complexes [20,21].

\section{Magnetic properties}

Magnetic susceptibilities for a powdered sample of the complex were measured with a SQUID magnetometer over the temperature range 4.6-301 K. The magnetic susceptibilities of the complex are shown as a function of temperature in Fig. 4. The data were fitted using the Bleaney-Bowers equation [22]

$$
\begin{aligned}
\chi= & \frac{N_{L} g^{2} \mu_{B}^{2}}{3 k T}\left[1+\frac{1}{3} \exp (-2 J / k T)\right]^{-1}\left(1-x_{p}\right) \\
& +\frac{N_{L} g^{2} \mu_{B}^{2}}{4 k T} x_{p}+N_{\alpha}
\end{aligned}
$$

and the isotropic (Heisenberg) exchange Hamiltonian $\mathrm{H}=-2 J \quad \mathrm{~S}_{1} \cdot \mathrm{S}_{2}$, where $-2 J$ corresponds to the energy separation between spin-singlet and -triplet states, for two interacting $\mathrm{S}=1 / 2$ centers. $N_{\alpha}$ is the temperature-independent paramagnetism and its value is $6.10^{-5} \mathrm{~cm}^{3} / \mathrm{mol}$ for each copper atom. $x_{p}$ is the molar fraction of a monomeric impurity. Least squares fitting of the data leads to $J=-10.5 \mathrm{~cm}^{-1}$, $\mathrm{g}=2.06, x_{p}=1.6 \%$. The title compound shows a maximum in magnetic susceptibility at ca. $12.1 \mathrm{~K}$ $\left(0.032 \mathrm{~cm}^{3} \mathrm{~mol}^{-1} \mathrm{~K}\right)$ which is typical of antiferromagnetic behavior. The rapid increase in magnetic susceptibility at low temperatures is due to the presence of a small amount of monomeric impurity (1.6\%) as commonly encountered is such systems [23]. The calculated magnetic moments values $\left[\mu_{\text {eff }}=2.828(\chi \mathrm{T})^{1 / 2}\right]$ decrease from a value of $0.82 \mu_{\mathrm{B}}$ at $301 \mathrm{~K}$ to $0.025 \mu_{\mathrm{B}}$ at $4.6 \mathrm{~K}$, indicating a moderate intramolecular antiferromagnetic interaction.

In general, several structural features of binuclear copper(II) complexes are thought to regulate the strength of exchange coupling interactions: (i) the dihedral angle between the two coordination planes, (ii) planarity of the bonds around the bridging atom, and (iii) the bridging atom(s) and bridging angles [24, 25]. However, the number of polynuclear copper(II) complexes with piperazine-derivative is very limited to draw magneto-structural correlations. The observed antiferromagnetic coupling between the copper(II) ions is propagated by the piperazine bridge through a $\sigma$ type of exchange pathway. This through-bond coupling (via the two intervening $\mathrm{C}-\mathrm{C}$ bonds) has been already reported for very few complexes $[20,26]$. A simple comparison between structural and magnetic parameters of the title compound and related complexes $\left[\mathrm{Cu}_{2}(\mu\right.$ $\left.\mathrm{L})(\mathrm{DMF})_{2}\right]\left(\mathrm{ClO}_{4}\right)_{2}(\mathrm{DMF}=N, N$-dimethylformamide $)$ of the new piperazino $\mu$-bis(tridentate) ligand, $\left\{\mathrm{N}, \mathrm{N}^{\prime}-\right.$ bis[2-((salicylaldimine)amino)ethyl]piperazine $\}$ and $\left[\mathrm{Cu}(\right.$ fum $\left.)(\mathrm{ppz})\left(\mathrm{H}_{2} \mathrm{O}\right)_{2}\right]$ (fum = fumarate dianion and $\mathrm{ppz}=$ piperazine) reported recently $[21,26]$ confirms this similarity: The $\mathrm{Cu} \cdots \mathrm{Cu}$ bond distances are 6.908 and $6.947 \AA$; the $\mathrm{N}_{\text {pip }}-\mathrm{N}_{\text {pip }}$ distances are 3.038 and $2.963 \AA$; the $\mathrm{Cu}-\mathrm{N}_{\text {pip }}$ distances are 2.058 and $2.047 \AA$. In the investigated complex, the $\mathrm{Cu} \cdots \mathrm{Cu}$ bond distance is 6.954(3) $\AA$; the $\mathrm{N}_{\text {pip }}-\mathrm{N}_{\text {pip }}$ distance is $3.007 \AA$; the $\mathrm{Cu}-\mathrm{N}_{\text {pip }}$ distances is 2.101(3) $\AA$. The $J$ values reported from these studies are very close to that obtained in the present work: $J=-13.9 \mathrm{~cm}^{-1}$ and $-14.7 \mathrm{~cm}^{-1}$ and $\mathrm{g}=2.07$ and 2.04 , respectively.

\section{Extended Hückel molecular orbital calculations (EHMO)}

We have carried out extended Hückel molecular orbital calculations (EHMO) in order to gain in- 


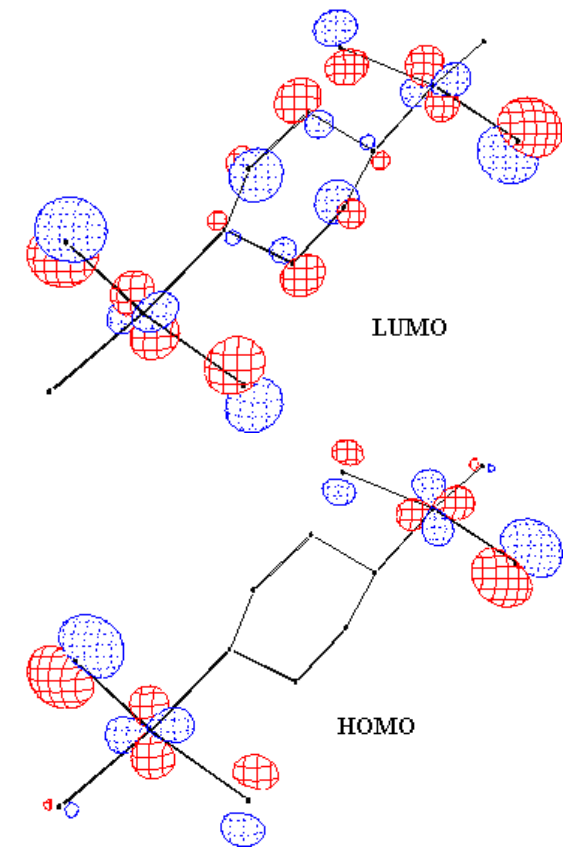

Fig. 5. Schematic representation of the LUMO and HOMO frontier orbitals for the investigated compound, obtained using the CACAO programme (for orbitals contributing more than $1 \%) .\left(\varepsilon_{1}-\varepsilon_{2}\right)=0.011 \mathrm{eV}$.

sight into the molecular orbitals that participate in the super-exchange pathway. EHMO calculations we reperformed from the crystallographic coordinates of the $\mathrm{Cu} 1, \mathrm{Cu} 1^{\mathrm{i}}, \mathrm{N} 1, \mathrm{~N}^{\mathrm{i}}, \mathrm{O} 1, \mathrm{O} 1^{\mathrm{i}}, \mathrm{C} 11, \mathrm{C} 11^{\mathrm{i}}, \mathrm{C} 10, \mathrm{C} 10^{\mathrm{i}}$, $\mathrm{C} 11, \mathrm{C} 11^{\mathrm{i}}, \mathrm{N} 2$, and $\mathrm{N} 2^{\mathrm{i}}$ atoms in the super-exchange pathway. An energy difference of $0.011 \mathrm{eV}$ is obtained between the highest occupied molecular orbital (HOMO) and the lowest unoccupied molecular orbital (LUMO). A graph of HOMO and LUMO orbitals for the investigated complex is depicted in Fig. 5. In both MOs the magnetic orbitals are mainly centered in the $\mathrm{d}_{x}{ }^{2}-y^{2}$ copper orbitals, in agreement with the geometry of the metal ions. The LUMO is delocalized on the atomic orbitals of the piperazine bridging ligand and shows bonding character $\left(\varphi_{1}\right)$ for the N-N overlap. On the other hand, in the HOMO, the delocalization on the piperazine ligand is less extended and the main feature is the antibonding $\left(\varphi_{1}\right)$ character of the $\mathrm{N}-\mathrm{N}$ overlap in the piperazine bridge. From Fig. 4 it is obvious that there is a good overlap between the $\mathrm{N}$ or- bitals of the piperazine (bonding and antibonding) in the HOMO and LUMO. The importance of this bonding and antibonding contributions to the orbitals of the piperazine is the main origin of the energy gap and thus, of the antiferromagnetic coupling. As the antiferromagnetic interaction increases, the two molecular orbitals $\varphi_{1}$ and $\varphi_{2}$ will separate in energy. The energy separation between these two new molecular orbitals is expected to determine the super-exchange coupling constant. According to the theoretical analysis by Hoffmann and co-workers [27,28], the coupling constant is expressed as

$$
2 J=2 K_{a b}-\frac{\left(\varepsilon_{1}-\varepsilon_{2}\right)^{2}}{J_{a a}-J_{a b}}
$$

where $K_{a b}, J_{a a}$ and $J_{a b}$ are the exchange integral and one-centre and two-centre Coulomb repulsion integrals, respectively, and $\varepsilon_{1}$ and $\varepsilon_{2}$ are the energies of the two orbitals $\varphi_{1}$ (HOMO) and $\varphi_{2}$ (LUMO), respectively. The value of $K_{a b}$ is always positive, so the first term in (2) contributes to the ferromagnetic interaction, while the second term, which is always positive, contributes to the antiferromagnetic interaction. The energy difference between the two molecular orbitals $\left(\varepsilon_{1}-\varepsilon_{2}\right)$ which corresponds to the HOMO-LUMO energy gap, determines the magnitude of the antiferromagnetic interaction. From the above expression (2) for the exchange parameter, it is seen that the binuclear complex with the greater antiferromagnetic interaction has the larger $\left(\varepsilon_{1}-\varepsilon_{2}\right)$ energy difference. The extended Hückel molecular orbital (EHMO) calculations have shown that the $\varphi_{1}$ and $\varphi_{2}$ orbitals are separated by $0.011 \mathrm{eV}$, respectively. Very recently, we have studied the crystal structures and magnetic properties of $(\mu$ hydroxo $)(\mu$-acetato $)$ and ( $\mu$-hydroxo $)(\mu$-pyrazolate) bridged dicopper(II) complexes [29,30]. For these binuclear copper complexes $\left(\varepsilon_{1}-\varepsilon_{2}\right)$ energy differences are found to be $0.605,0.645$ [29] and 0.648 [30] with the $-J$ values $81.8,89.6$ and $92.7 \mathrm{~cm}^{-1}$, respectively. These results indicate a stronger antiferromagnetic interaction than in the investigated compound, suggesting that a large energy separation of $\varphi_{1}$ (HOMO) and $\varphi_{2}$ (LUMO) leads to a strong antiferromagnetic interaction.
[1] K. D. Karlin, Z. Tyeklar (eds): Bioinorganic Chemistry of Copper, Chapman and Hall, New York (1993).

[2] L. Q. Jun, A. E. True, Prog. Inorg. Chem. 38, 97 (1990).
[3] D. Gatteschi, O. Kahn, R. D. Willet, Magnetostructural Correlations in Exchange Coupled Systems, Reidel, Dordrecht (1984). 
[4] O. Kahn, Angew. Chem. Int. Ed. Engl. 24, 834 (1985).

[5] O. Kahn, Struct. Bonding (Berlin) 68, 89 (1987).

[6] T.N. Doman, D.E. Williams, J.F. Banks, R.M. Buchanan, H. R. Chang, R. J. Webb, D. N. Hendrickson, Inorg. Chem. 29, 1058 (1990).

[7] T. Kawato, M. Yamanaka, S. Ohba, Y. Nishida, M. Nagamatsu, T. Tokii, M. Kato, O. W. Steward, Bull. Chem. Soc. Japan 65, 2739 (1992).

[8] U. Mukhopadhyay, L. R. Falvallo, D. Ray, Eur. J. Inorg. Chem. 2823 (2001).

[9] M. Boiocchi, M. Bonizzoni, L. Fabbrizzi, F. Foti, M. Licchelli, A. Taglietti, M. Zema, J. Chem. Soc., Dalton Trans. 653 (2004).

[10] Z. Smekal, Z. Travny'cek, J. Mrozinski, J. Marek, Inorg. Chem. Commun. 6, 1395 (2003).

[11] C. T. Zeyrek, A. Elmali, Y. Elerman, Z. Naturforsch. 60b, 520 (2005).

[12] C. T. Zeyrek, A. Elmali, Y. Elerman, Z. Naturforsch. 60b, 940 (2005).

[13] Enraf-Nonius diffractometer control software, Release 5.1, Enraf-Nonius, Delft, Netherlands (1993).

[14] G. M. Sheldrick, SHELXS-97, Program for the solution of crystal structures, Univ. of Göttingen, Germany (1997).

[15] G. M. Sheldrick, SHELXL-97, Program for the refinement crystal structures, Univ. of Göttingen, Germany (1997).

[16] L. J. Farrugia, ORTEPIII. J. Appl. Crystallogr. 30, 565 (1997).

[17] Further information may be obtained from: Cambridge Crystallographic Data Center (CCDC), 12 Union Road, Cambridge CB21EZ, UK, by quoting the depository number CCDC-283155, E-mail: deposit@ ccdc.cam.
[18] A. Weiss, H. Witte, Magnetochemie, Verlag Chemie, Weinheim (1973).

[19] C. Mealli, D. M. Proserpio, CACAO, Computer Aided Compositon of Atomic Orbitals, a Package of Programs for Molecular Orbital Analysis, PC Version 4.0, July (1994). Original Reference: J. Chem. Educ. 67, 399 (1990).

[20] B. Chiari, O. Piovesana, T. Tarantelli, P. F. Zanazzi, Inorg. Chem. 23, 2542 (1984).

[21] M. Bera, J. Ribas, W. T. Wong, D. Ray, Inorg. Chem. Commun. 7, 1262 (2004).

[22] C. J. O’Connor, Prog. Inorg. Chem. 29, 203 (1982).

[23] W. Mazurek, B. J. Kennedy, K. S. Murray, M.J. O'Connor, J.R. Rodgers, M.R. Snow, A. G. Wedd, P. R. Zwack, Inorg. Chem. 24, 3258 (1985).

[24] T. Kawata, H. Uekusa, S. Ohba, T. Furukawa, T. Tokii, Y. Muto, M. Kato, Acta Crystallogr. B48, 253 (1992).

[25] V. H. Crawford, H. W. Richardson, J. R. Wasson, D. J. Hodgson, W.E. Hatfield, Inorg. Chem. 15, 2107 (1976).

[26] P. S. Mukherjee, S. Dalai, G. Mostafa, E. Zangrando, T. Lu, G. Rogez, T.-H. Mallah, N. R. Chaudhuri, Chem. Commun. 1346 (2001).

[27] P. J. Hay, J. C. Thibeault, R. Hoffman, J. Am. Chem. Soc. 97, 4884 (1975).

[28] R. W. Jotham, S. F. A. Kettle, Inorg. Chem. 9, 1390 (1970).

[29] E. Kavlakoglu, A. Elmali, Y. Elerman, Z. Naturforsch. 57b, 323 (2002).

[30] A. Elmali, C. T. Zeyrek, Y. Elerman, J. Mol. Struct. 693, 225 (2004). 